\title{
Aspects of Spectral Analysis of Biofield
}

\author{
Bryndin EG*1 and Putmakov $\mathrm{AN}^{2}$ \\ ${ }^{1}$ Research center, "ESTESTVOINFORMATIKA", Russia \\ ${ }^{2}$ VMK Optoelektronika, Enterprise MedTech, Russia
}

*Corresponding author: Bryndin EG, Research center "ESTESTVOINFORMATIKA", Novosibirsk, Russia

\begin{tabular}{|c|c|}
\hline ARTICLE INFO & ABSTRACT \\
\hline Received: 蔧 March 15, 2019 & Modern scientific knowledge perceives a biofield of the person mainly as biopower, \\
\hline Published: March 25, 2019 & $\begin{array}{l}\text { tied, mainly, to functioning of a biological body, in general, and its separate bodies and } \\
\text { cages in particular that is connected with power radiations of bodies and cells of a }\end{array}$ \\
\hline $\begin{array}{l}\text { itation: Bryndin EG, Putmakov AN. } \\
\text { spects of Spectral Analysis of Biofield. }\end{array}$ & $\begin{array}{l}\text { of the person in the course of his spiritual ascension intensify development of the } \\
\text { corresponding methodologies of a pilot study of the mental power phenomena. }\end{array}$ \\
\hline
\end{tabular}

Biomed J Sci \& Tech Res 16(2)-2019. BJSTR. MS.ID.002835.
Keywords: Biofield; Spectral Analysis; Research Technique; Mental Power Component

\section{Introduction}

Mental energy the term, is offered by S. Freud for the description of specifics of movement of attention, interest and attachment from one object (or the current activity) on another. In definition Moore Fayna mental energy is the cornerstone of any activity of the mental device and all mental manifestations. Power basis of activity of all people one. Programs of behavior of any person are formed by reason and are implemented by mental energy. Soul is filled with mental energy. Mental energy reaches each section. Mental tool energy provides the movement of blood, functioning of an organism and through nervous and muscular system forms behavior of the person in his activity. The main functions of mental energy are divided into two groups: motivational and tool. The motivational group is formed as accumulation of the mental energy of a biofield, in the form of the detainee remaining capable to make work. Tool function serves for realization of various mental processes.

\section{The Mental Power Component of Biofield}

The mental power component of biofield of the person is formed by these or those motivations activating in the course of activity, emotions, thoughts, strong-willed impulses, etc., each of which at activation radiates waves of a certain power spectral and color frequency. To each power spectral and color frequency there corresponds, quite certain power spectral and color "vibration" frequency. It is known that the mental power radiations which are shown in a biofield of the person at activation in it congenital animals (biological and physiological) instincts and motivations tied to them, emotions and thoughts, are characterized by lower power spectral and color frequency of vibrations, and to them there corresponds more dark color spectral scale: dark gray, graybrown, brown and others "muddy infrared" tone. The mental power radiations arising in a biofield of the person at activation of the motivations, emotions and thoughts induced by prisoners in mental nature of the light, conscientious party of its spiritual nature - intimate super conscious levels of its spirit - high frequency also belong to the range ultra-violet spectral color: violet, blue, blue, golden-yellow, red, pink, ruby, silver-white colors. Respectively, the person from the expressed animal and instinctive prepotent has more low-frequency and more darkened, in the spectral and color relation, aura. The person from the expressed his superconscious prepotent spiritual nature has more high-frequency, shining in bright iridescent ultra-violet spectral flowers.

Therefore, with strengthening and the beginning of domination in the person of the light, conscientious party of his nature, in the range of its mental power radiations more high-frequency ultra-violet radiations will begin to amplify and prevail, i.e. the phenomenon of shift of frequencies of mental power radiations of the person towards more high-frequency ultraviolet spectrum has to take place. And with strengthening and the beginning of domination in the person of the low animal and instinctive party of his congenital dual mental nature - the phenomenon of shift of frequencies of its mental power radiations towards more lowfrequency infrared zone of a range has to take place. The pilot study 
of the phenomena of ultra-violet and infrared shift of frequencies of mental power radiations of the person in the course of his spiritual ascension (evolution) or degression (involution), respectively, is the major task facing modern natural sciences which research and the decision is already quite feasible by means of modern high technologies. Experimental confirmation of reliability of these phenomena - already in itself is a substantial contribution to natural-science justification of reliability of these basic provisions of diagnostics of a biofield. The spectral analysis of mental power radiations of the person allows to diagnose, along with a condition of his biological health, and a condition of its spiritual development and a spiritual state. The method of the combined spectral and frequency analysis can define - whether low-frequency radiations, or ultrahigh-frequency radiations of the highest levels of spirituality dominate in a range of power radiations of a biofield of the person. Concrete spectral and frequency characteristics and approaches to their measurement are important for definition of a condition of spiritual development of the person [1-5].

\section{Color range of a biofield and ability of the person}

The biofield forms a power aura, shine of a body of the person which is created by his power. The luminescence of a biofield or shine of aura is formed due to work of the power centers of the person. The range of energy filling a biofield reflects in itself all information on the person, a condition of a present situation and information on states last. Can determine by a luminescence and a form of a biofield what power prevails in the person what power centers work stronger and what function poorly. It is possible to determine by shine in what state and mood there is a person whether he is healthy. Also negative impacts on the person are determined by a luminescence of a biofield of the person. In ideal option at the harmonious spiritually developed person the biofield has 7 layers. On number of the main working power centers. But in practice such people meet extremely seldom. Most of people functions on 2 - 3 types of energy, not to seek for self-development and increase in abilities and energy and is limited to the minimum set of energy. Each layer of a biofield is a possession of a certain type of energy and respectively certain tendencies, abilities and opportunities.

Red color of a biofield appears at big physical activities, at muscular activity, at physical overfatigue or at negative psychological states: aggression, a condition of a severe stress, a fright or rage, testifies to negative serious condition, to reflection on negative subjects. Pink color of a biofield is formed by the emotional excitement, a state which is adjusted on communication, an emotional positive state. Yellow color - color of mind, reasonings, thought processes, focus on any business. Green, gently green color of warm experiences, demonstrates that the person takes everything very much to heart - responsibility, commitment, personal experiences, thoughts and care of the family. Blue color of mental energy of creativity, positive mental energy. People with blue color possess strong mentality and nervous system, rich imagination and strongly developed figurative thinking. Blue color demonstrates will of the person, his power of thought, intellectuality and ability to influence the world around and to change it. Violet color testifies to high degree of an intuition, ability to use spiritual energy. The white sparkling color demonstrates sanctity of the person.

These are the primary colors speaking about work of the power centers and a condition of a biofield of the person. Actually shades of flowers of energy of a biofield and options of their set huge set. To understand what happens to the person what power prevails whether the power centers correctly work. Whether there are no hidden problems, threats, leakages of energy, it is necessary to carry out the spectral analysis of a biofield of the person.

Any negative (negative emotions, negative thought forms) is heavy power which has property, collects in power of a biofield. And even when a life situation and your state of mind already changed to the best the collected negative remains in a biofield around you and returns you to bad behavior. The biofield is power integrity, security and the atmosphere in which you live. In other words, it is your power lodge, your personal space which always is at you. And the house and the space it is necessary to keep clean (Figure 1).

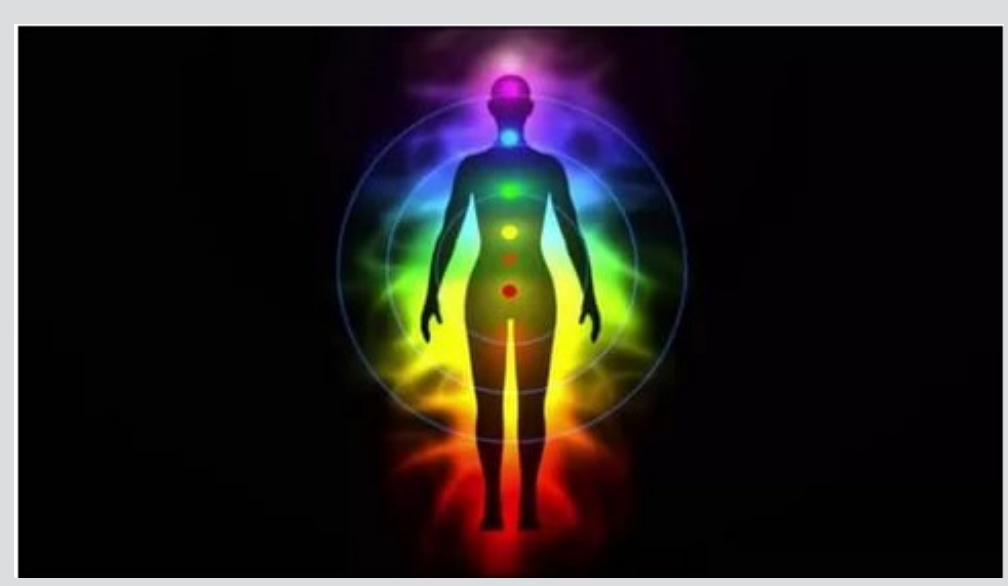

Figure 1: Clean biofield of the person. 


\section{Spectral Analysis of Biofield}

Based on the GRV method - it is possible for gas-discharge visualization of radiations of a biofield of the person (by the Kirlian method) quickly and with high precision to find changes of field structures and potentials of power radiations of biological bodies (Figure 2). What allows to diagnose effectively diseases of the person at a donozologiya stage. Destructive radiations appear at the person as a result of action of its negative spiritual qualities or emotions: *the grief gives vibrations - from 0.1 to 2 hertz; ${ }^{*}$ fear from 0.2 to 2.2 hertz; *offense -from 0.6 to 3.3 hertz; *irritation - from 0.9 to 3.8 hertz; *indignation -from 0.6 to 1.9 hertz; *the egoismgives vibrations of at most 2.8 hertz; *irascibility (irascibility)
- 0.9 hertz; *flash of rage - 0.5 hertz; anger- 1.4 hertz; *arrogance - 0.8 hertz; pride -3.1 hertz; *neglect -1.5 hertz; *superiority -1.9 hertz; *pity -3 hertz. Researchers on physical medicine noticed long ago that positive people who lead a healthy lifestyle are not ill when the frequency of vibrations of their power field was included into a resonance with a frequency of vibrations of 8 hertz. Throughout the millennia the frequency of vibrations (fluctuations in a second) our planet was 7.8-8.2 Hz. Physicists call it Schuman's frequency. It fluctuates within 8 hertz. The resonance of standing electromagnetic waves with a frequency of 8 hertz of a biofield provides and supports a healthy condition of an organism. Health to the person is provided by the clean nature and spiritual and naturalistic practice of a healthy lifestyle [5].

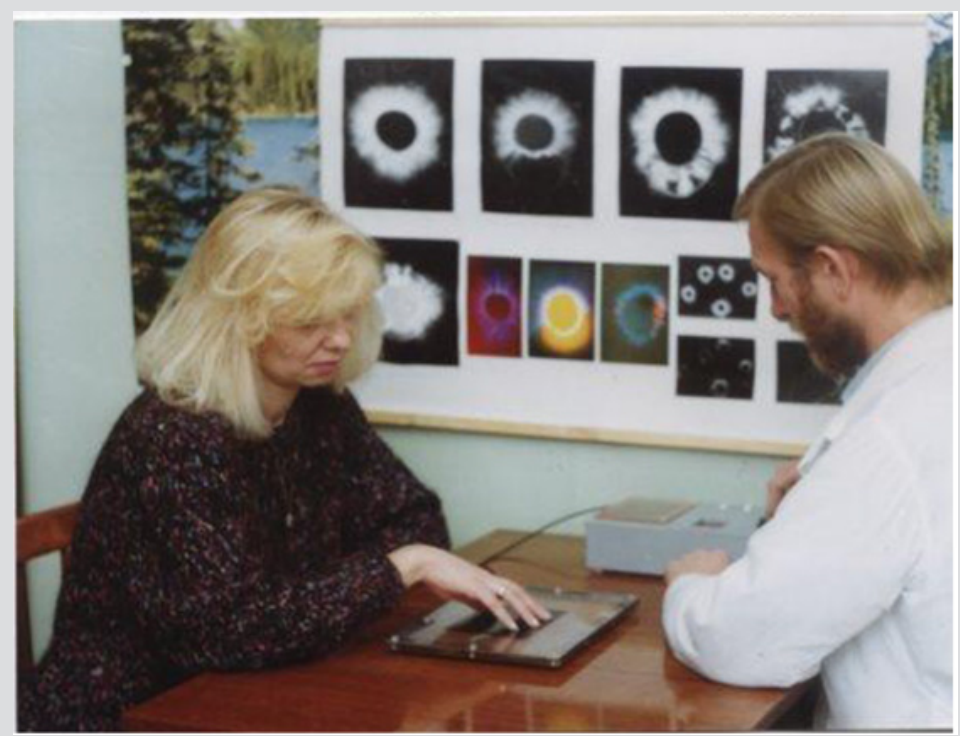

Figure 2: Bio diagnostics.

\section{Conclusion}

Spiritual and naturalistic practice and spectral diagnostics of a biofield of the person form the new direction of health care providing healthy longevity.

\section{References}

1. Jenkins G, Watts D (1972) Spectral analysis and its applications. M World 2: 317 .

\section{ISSN: 2574-1241}

DOI: 10.26717/BJSTR.2019.16.002835

Bryndin EG. Biomed J Sci \& Tech Res

cC (P) This work is licensed under Creative Commons Attribution 4.0 License

Submission Link: https://biomedres.us/submit-manuscript.php
2. Putmakov AN (2005) About Expansion of opportunities of the issue spectral analysis and the existing restrictions. Journal: ANALYTICS AND CONTROL Yekaterinburg: UFU 9(2): 141-146.

3. Bobrov AV (2007) Model research of the field concept of the mechanism of consciousness. Eagle: GTU, pp. 261.

4. SA Kostryukov (2012) Development of a technique for studying of a biofield of the person. Biotechnosfera Ryazan: RGRU 1: 55-61.

5. Bryndin EG (2018) Psychological and Social Aspects Formations of Thinking, Consciousness and Behavior. SM Physical Medicine \& Rehabilitation 2(1): 1-5.

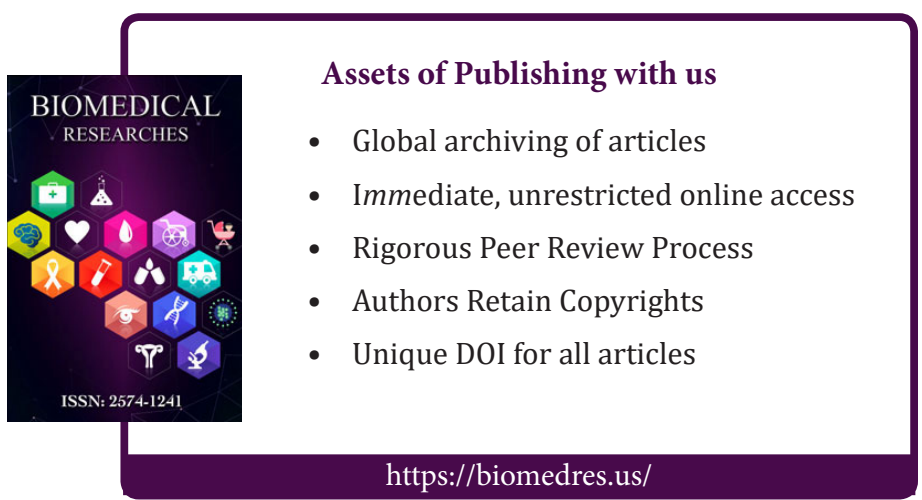

